\title{
Tocar nas coisas e resgatar paraísos perdidos: voltar ao teatro com o Descon'FIMFA
}

\author{
CATARINA FIRMO
}

Título: La melancolia del turista. Criação, construção e interpretação: Shaday Larios, Jomi Oligor. Colaboração poética: Ángel Hernández. Colaboração inventiva: Ivan Puig, Jordi Fondevila. Colaboração musical e sonora: Suetszu \& Jayrope. Desenhos: Pepe Oligor. Fotografias: Oligor y Microscopia, David Continente. Co-produção: Oligor y Microscopía, Patronato Municipal de las Artes Escénicas y de la Imagen del Ayuntamiento de Zaragoza, Iberescena, Festival Grec de Barcelona, Le Parvis, Temporada Alta 2019 e Pyrenart. Data e local de estreia: 19 de Novembro de 2019, Festival Temporada Alta de Girona. Estreia nacional: 5 de Agosto de 2020, Descon'FIMFALx20.

Título: La maquina de la soledad. Criação, construção e interpretação: Shaday Larios, Jomi Oligor. Co-produção: Oligor y Microscopía, Centre d'Arts Escèniques de Terrassa, Iberescena. Com a colaboração de: La Máquina de Teatro. Fotografias: Oligor y Microscopía, Alípio Padilha. Data e local de estreia: 14 de Agosto de 2014, Teatro El Rinoceronte Enamorado (México). Estreia nacional: 14 de Maio, FIMFALx15. Apresentado em 12 de Agosto de 2020 no Descon'FIMFALx20.

SAIR. TOCAR NAS COISAS.

Quién ha tocado esto que yo toco? SHADAY LARIOS

Entre 5 de Agosto e 5 de Setembro de 2020, decorreu o Descon'FIMFA Lx2O, um dos primeiros festivais de teatro que vivenciamos em pandemia (um mês antes, já tínhamos começado a espantar o medo com a $37 .^{\mathrm{a}}$ edição do Festival de Almada). Forçados a cancelar o FIMFA Lx2o programado para Maio, quando celebravam duas décadas, Rute Ribeiro e Luís Vieira programaram uma edição especial de Verão, lançando o convite para desconfinar pelo universo das formas animadas. Os dois

Shaday Larios coloca a pergunta aludindo a um artigo de Cristina Rivera Garza «Del verbo tocar: Las manos de la pandemia y las preguntas inescapables», publicado na Revista da Universidade do México em junho de 2020. 
primeiros espetáculos da programação foram La Melancolia del Turista e La maquina de la soledad, da dupla Oligor y Microscopia. A companhia, criada em 2013, é fruto do encontro entre Shaday Larios (Microscopia Teatro, México) e Jomi Oligor (Hermanos Oligor, Espanha) num festival de teatro em São Paulo, onde reconheceram o interesse partilhado por objetos, memória, miniaturas e fragilidade. Interessados em investigar as capacidades documentais de objetos aparentemente insignificantes, fundaram o grupo de pesquisa «Agencia El Solar Detetives de objetos Praticas de territorio e cultura material», em colaboração com Xavier Bobès (Cia Playground, Espanha).

Paralelamente ao percurso da companhia, importa aqui dedicar algum tempo para dar a conhecer o trabalho de investigação desenvolvido por Shaday Larios, sobre a dimensão poética, filosófica e criativa dos objetos nas suas relações com a memória, os discursos e as comunidades. ${ }^{2}$ Assumindo-se como objetóloga, desenvolve uma investigação-criação sobre o teatro de objetos documentais, explorando as ligações entre os conceitos de memória, bairro, cena e objetos quotidianos. Autora das obras Escenarios post-catástrofe: filosofía escénica del desastre (2010), Los objetos vivos. Escenarios de la materia indócil (2018) e Detectives de objetos (2019), articula a pesquisa académica com a criação, em trabalhos de campo focados em biografias que interrogam a memória individual e coletiva dos lugares e comunidades. No artigo «Casa y Teatro de Objetos: Intimidad del espacio doméstico en tiempos de guardar distancia», publicado em abril de 2020 na plataforma Titeressante, a autora discorre sobre os modos de libertação dos corpos detidos entre as coisas e as paredes durante o tempo de confinamento, alertando:

Podríamos hacer un inventario de historias de objetos encontrados, redescubiertos o recuperados en nuestras casas durante este encierro y que han venido a reclamarle o a confirmarle algo al curso de nuestras vidas en el presente. Porque casi cualquier objeto es capaz de abrirnos un potencial vital cuando la subjetividad que lo percibe se desacelera. (Larios, 2020)

Os espetáculos de Oligor y Microscopia situam-nos num ambiente de intimidade e reclamam estados de escuta e atenção ativos, guiando-nos

2 Shaday Larios foi reconhecida com o Premio Internacional de Ensayo Teatral 2010 do Instituto Nacional de Bellas Artes CITRU-Paso de Gato ARTEZ com a obra Escenarios post-catástrofe: filosofía escénica del desastre.

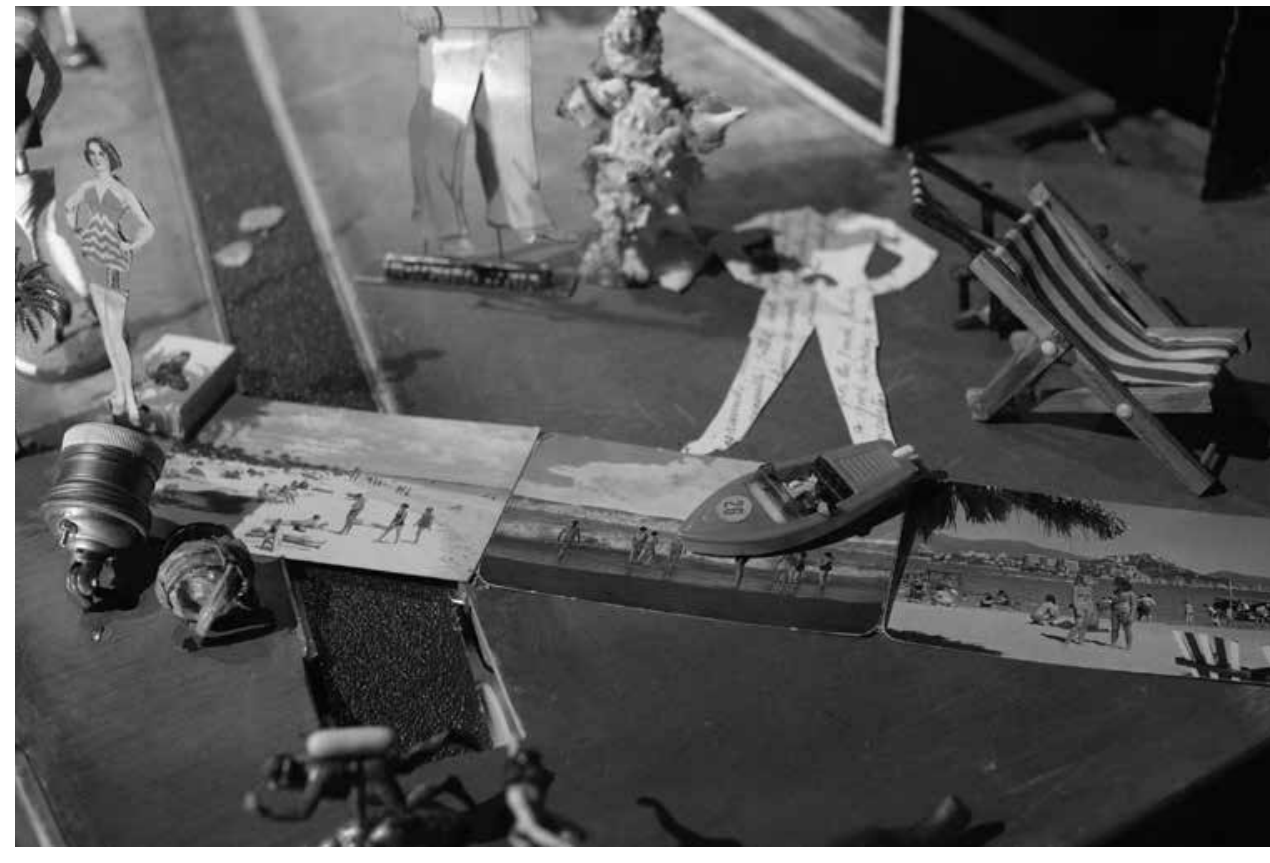

LA MELANCOLIA DEL TURISTA, JOMI OLIGOR E SHADAY LARIOS, OLIGOR Y MICROSCOPIA, 2019, [F] ALİPIO PADILHA

pelas suas histórias com vagar, dando tempo a cada objeto e pormenor para que se possam expandir. A dramaturgia das suas criações parte da recolha de objetos em feiras de antiguidades e nos lugares e comunidades percorridos durante as suas viagens de pesquisa. Os objetos-documentais tornam-se materiais de criação, portadores de experiências e veículos de narrativas para reconstruir as lembranças de outras vidas.

A palavra «microscópio», contida no nome da companhia, remete desde logo para o gesto da miniatura ampliada e refletida; é um gesto condutor nas suas criações, onde cada elemento é observado e projetado, num jogo de espelhos, luzes e sombras, explorando as perspetivas desencadeadas pela diversidade de escalas e formas.

DIAS DE SUSPENSÃO

La melancolia del turista é uma criação que parte de um trabalho de pesquisa nas cidades de Acapulco e Havana, focando-se sobre o modo como esses destinos turísticos entraram em declínio. Não deixou de ser curioso experienciar o desconfinamento com um espetáculo que fala sobre 
cidades vazias, espaços abandonados que reclamam por ser vividos e onde a única forma de os fazer viver é através da memória do que foram. Também Lisboa se revelava desde esse março de 2020 num tempo suspenso, fazendo-nos recuar à memória de pelo menos duas décadas, quando em agosto se andava nas ruas desertas, quando os turistas se pareciam mais com viajantes e menos com turistas. É justamente sobre essa contradição de viajar e fazer turismo que refletem Shaday Larios e Ángel Hernández, no texto que ancorou o espetáculo e que apresentam como um diário de viagens:

Intentamos ser viajeros, pero nos Ilamaron turistas. Y nos dejamos Ilevar por la contradicción. Que imágenes suena nuestro cansancio? Fuimos a paisajes que desearon fijarse en el tiempo y ahora deshacen instatáneamente su memoria. Ahí nos convertimos en una mancha más. Y no sabemos realmente qué fue lo que trajimos de vuelta, qué fué lo que quedó. (Larios/Hernández, 2019: 15)

O livro La Melancolia del Turista é dedicado a Guillermina e a El Peque, as duas personagens encontradas nas viagens de Acapulco e Havana, cujas vidas e rotinas foram durante décadas focadas na circulação de turistas. Em Acapulco, conheceram El Peque (Juan Obrégon), famoso clavadista do penhasco La Quebrada, onde a atração turística recai sobre os mergulhadores de várias idades que escalam o rochedo, saltando para o mar com alturas impressionantes que chegam a atingir 35 metros. Relatando o encontro com El Peque, destacam o único dia em que o clavadista não sentiu medo ao saltar. Era um dia de chuva, em que a baía de La Quebrada estava vazia e não havia ninguém para assistir ao seu salto.

Deixaram de se vender os postais com os clavadistas, pois hoje em dia são imagens multiplicadas pelas câmaras e smartphones e porque se foi perdendo o hábito de escrever postais. São lidos e projetados alguns postais, revelando narrativas de momentos felizes, antes de o turismo ter entrado em declínio:

Agosto de 1979. Silvia, esto es lo màs bonito que he visto. Te diré que la ropa aquí casi no se usa. Es un buen sitio para tu máquina fotográfica. [...] Mayo de 1990. Un abrazo muy fuerte desde este país tan interessante y tan lleno de contradicciones. (Larios/Hernández, 2019: 24)

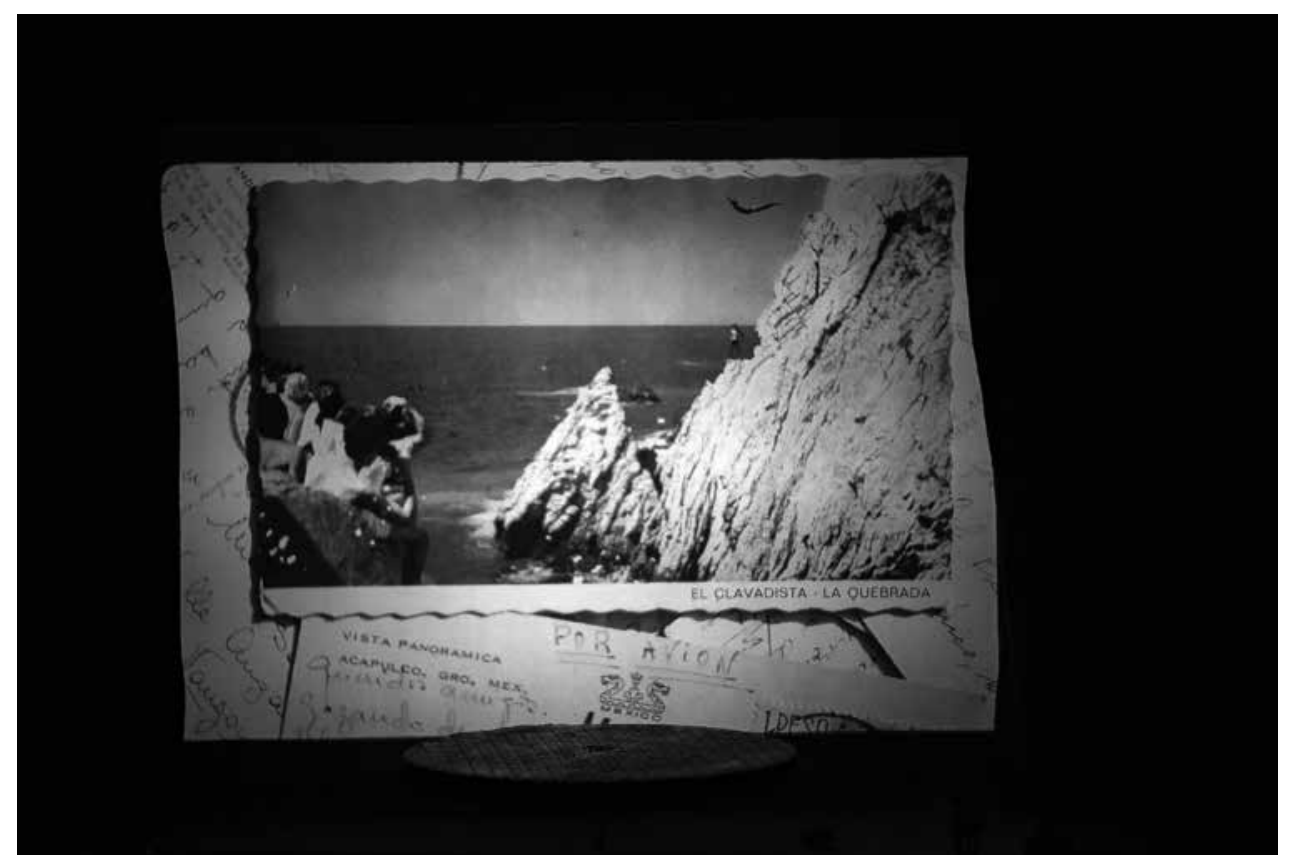

LA MELANCOLIA DEL TURISTA, JOMI OLIGOR E SHADAY LARIOS, OLIGOR Y MICROSCOPIA, 2019, [F] ALÍPIO PADILHA

Os letreiros dos hotéis de Acapulco ilustram o abandono da cidade, com palavras fragmentadas, onde apenas algumas letras são iluminadas. Para os detetives de objetos, decifrar as mensagens dos letreiros torna-se um motor para reconfigurar o seu passado e as histórias que aí se viveram: «Los letreiros están tristes. En el hotel Caribe, se desprende la L de hotel, la $\mathrm{E}$ de hotel, entonces HOT, HOT sin EL, una letra carcomida muda dialoga para sí adentro más adentro» (Larios/Hernández, 2019: 21).

O segundo destino escolhido foi a cidade de Havana, onde encontram Guillermina Delis Barrientos, que, durante sessenta anos, se sentou na mesma esquina da Rua da Amargura, a fumar charutos cubanos, trabalhando como figurante para as fotografias dos turistas. Hoje em dia, não encontra ninguém disposto a pagar-lhe por uma fotografia.

Que imagens se produzem a partir das ideias de descanso e melancolia associadas aos lugares onde passamos férias? Que memórias se criam nesses momentos efémeros, quando o tempo se suspende? As paisagens e as histórias dos paraísos perdidos são reescritas, a partir dos objetos e imagens recolhidas, vinculados a momentos felizes. Mas, mais ainda do que a recriação dessa experiência, o espetáculo foca a intensidade da recordação refletida no sentimento de melancolia definido como um 


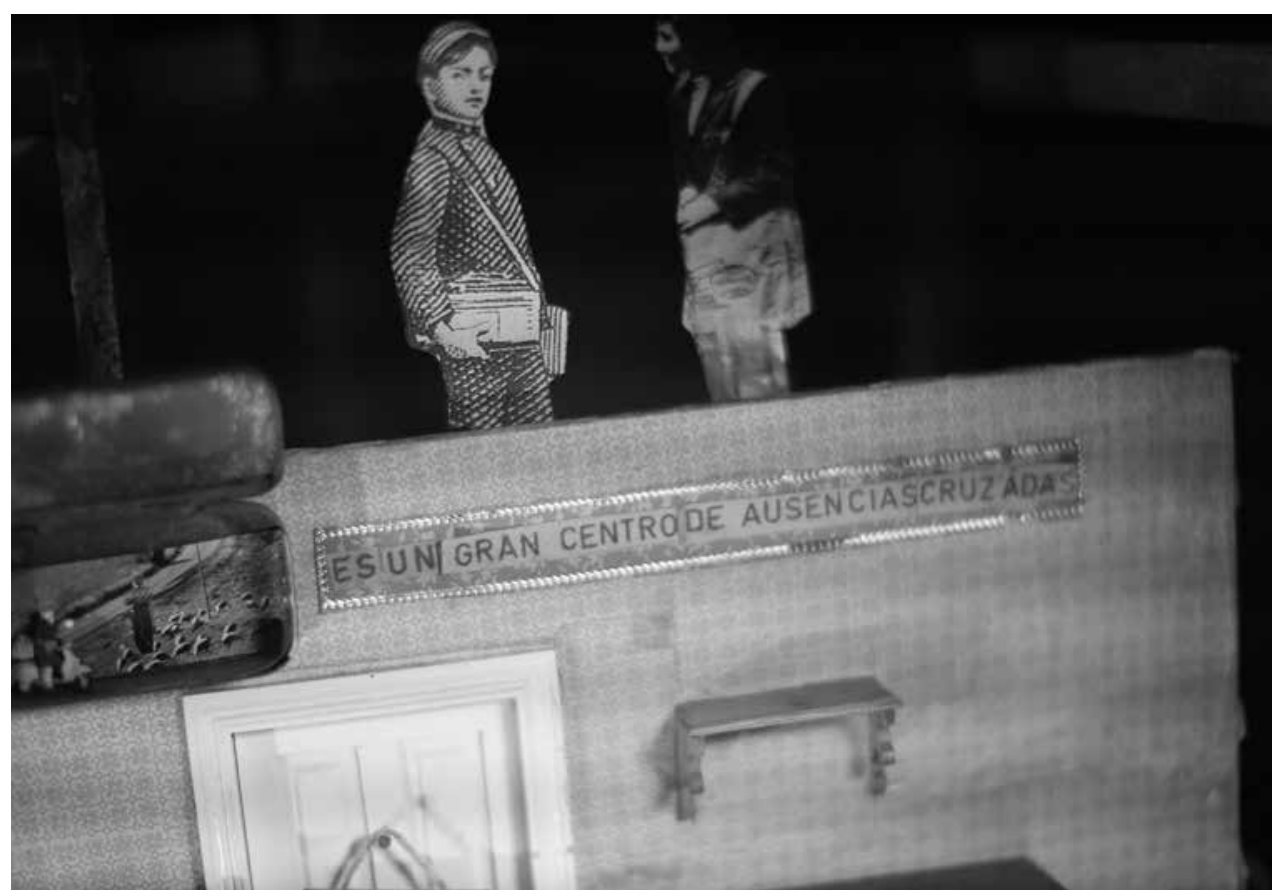

LA MAQUINA DE LA SOLEDAD, JOMI OLIGOR E SHADAY LARIOS, OLIGOR Y MICROSCOPIA, 2014, [F] ALÍPIO PADILHA

estado anímico suspensivo, onde reside uma força ativa para nos reinventarmos (Larios/Hernández, 2019: 110).

Acapulco e Havana são narradas pelas marcas da melancolia, resgatando os paraísos perdidos que definiram esses lugares no passado. Junto às praias, as boias e os colchões insufláveis flutuam no ar suspensos por cordas, manuseados pelos vendedores, sem nunca tocarem no mar. La melancolia del turista recorda-nos que um paraíso perdido não está verdadeiramente perdido. A melancolia que carrega o lugar transformado, conotado como paraíso perdido, gera novos lugares imaginados, territórios invisíveis e desobedientes:

un paraíso perdido en realidade no está perdido, há ganado un território invisible en la creencia de esa perdida, mientras por fuera el paraíso perdido es vasto, por dentro es pequeño, por dentro es desobediente en su apariencia, Detrás de todo paraíso perdido, actos mínimos toman la fuerza de lo que no se borró de la memoria, para volver a una imagen desconocida, que habita en el instante oscuro de la intermitência de un letreiro antes luminoso. (Larios/ Hernández, 2019: 22)

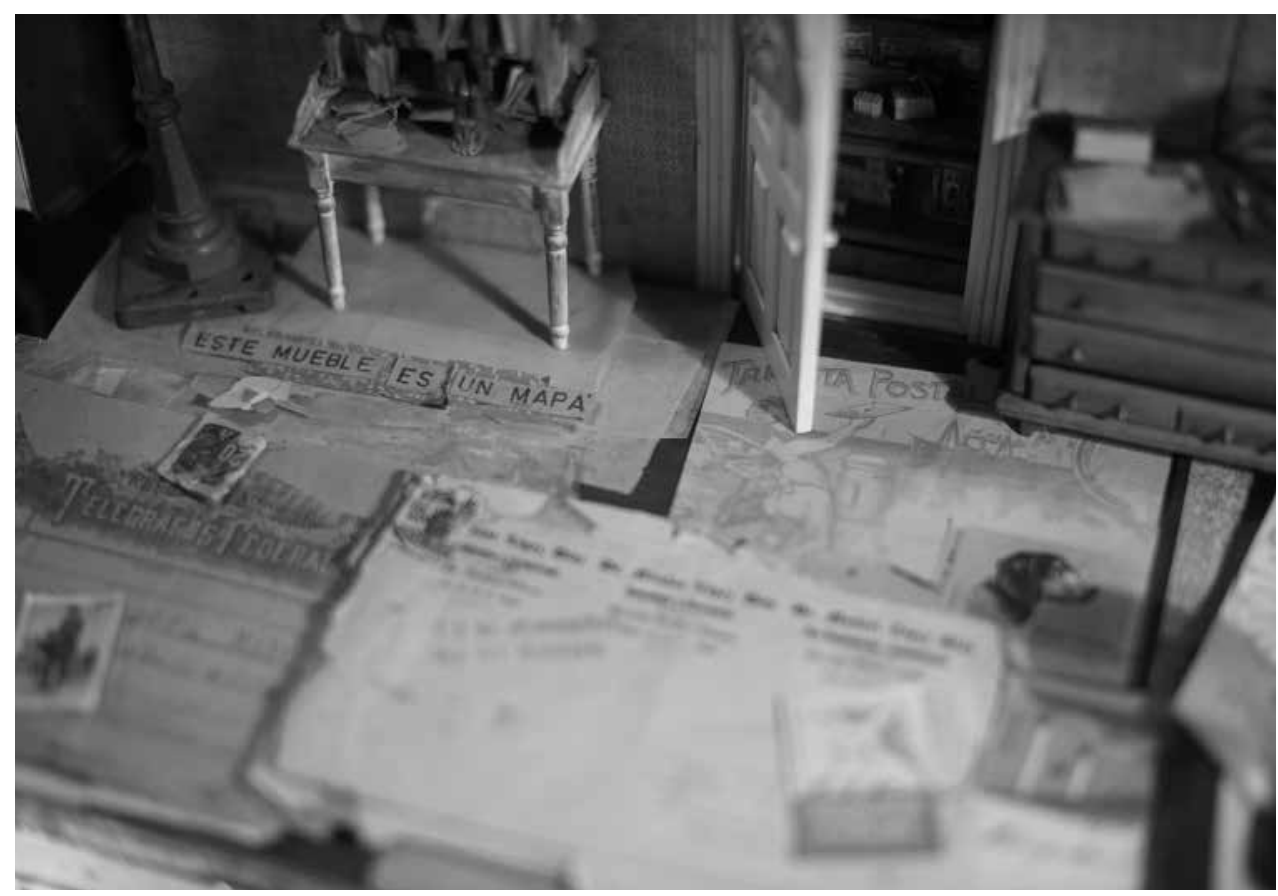

LA MAQUINA DE LA SOLEDAD, JOMI OLIGOR E SHADAY LARIOS, OLIGOR Y MICROSCOPIA, 2014, [F] ALÍPIO PADILHA

\section{SEISCENTAS CARTAS DE AMOR. PARTILHAR ESPACOS, TROCAR DE OBJETOS}

Um dia, Jomi Oligor e Shaday Larios encontraram uma mala com seiscentas cartas de amor de 1900, numa feira de antiguidades na Cidade do México. A leitura das cartas revelou-lhes a história do casal Manuel e Elisa que se corresponderam com seiscentas cartas durante um ano. A partir dessa descoberta, gerou-se a criação de La maquina de la sole$d a d$, um espetáculo homenagem ao objeto carta e ao correio postal. Além das cartas trocadas pelo casal de namorados, foram recolhidas histórias insólitas investigadas junto de carteiros reformados e nos arquivos dos correios: escribas que transcrevem mensagens e que são guardiões de segredos; carteiros que intercetam cartas, colecionando-as e espiando a intimidade dos outros, inventando forçosamente outras versões para essas vidas recolhidas e colecionadas.

A leitura das cartas situa-nos no espaço íntimo da confissão, nutrido pela ausência e pela distância, no tempo vagaroso da espera. Revelam ainda os caminhos percorridos para os encontros secretos de Manuel e Elisa, desvendando uma cartografia da cidade de há dois séculos, que nos permite reconstruir os bairros e o quotidiano vivido nessa época. 
Percorremos as marcas do tempo, transportados por histórias vividas e imaginadas, através de objetos simbólicos que indicam o itinerário da narrativa. Cada elemento em miniatura permite cristalizar e tecer o tempo, dar forma às memórias individuais e coletivas; conduzem-nos aos lugares evocados, que testemunham o que se viveu, por onde se passou. Contrariando a ideia de um presente contínuo, os objetos documentais são deslocados do seu valor utilitário e mercantil, sublinhando o seu significado simbólico e afetivo para iluminar as vidas que os manusearam.

Paralelamente à criação de La maquina de la soledad, a dupla Oligor y Microscopia prossegue a investigação focada no objeto carta, nos ofícios dos escribas e carteiros e no ritual epistolar, contando com a adesão de espectadores que têm enviado histórias, cartas e documentos, enriquecendo o seu arquivo3:

Desde que comenzamos este proyecto, hemos recibido por parte de amigos y espectadores, paquetes de cartas encontrados en mercados, rastros, lugares abandonados, etc. Sin darnos cuenta, nos hemos vuelto coleccionistas de documentos íntimos, de vidas narradas por sí mismas que revelan un cierto estado de las cosas, dentro de un territorio específico. Nos interesa recuperar lo que hay en algunas de ellas de "documentos históricos", en el sentido de que son evidencias, testimonios de aspectos culturales y socio-políticos que dan cuenta de fenómenos colectivos. ${ }^{4}$

Os objetos recolhidos e respigados são entendidos como veículos de memórias, confrontando diferentes épocas, lugares e histórias de vida, numa arqueologia dedicada a recriar matérias e reconstituir ruínas, insuflando vida nas paisagens e lugares abandonados. Shaday Larios e Jomi Oligor escolheram visitar os lugares para deles colher narrativas e escutar o que os objetos do passado reclamam hoje.

\section{REFERÊNCIAS BIBLIOGRÁFICAS}

GARZA, Cristina Rivera (2020), «Del verbo tocar: Las manos de la pandemia y las preguntas inescapables» Revista da Universidade do México, junho de 2020, https://www.revistadelauniversidad.mx/articles/6428d816-f2cf-42od-977e-c9cof8fc7427/del-verbo-tocar-las-manos-de-la-pandemia-y-las-preguntas-inescapables, consultado em 28/9/2020.

LARIOS, Shaday, e HERNÁNDEZ, Ángel (2019), La Melancolia del Turista, Oligor y Microscopia, Segovia, La Uña Rota.

LARIOS, Shaday (2020), «Casa y Teatro de Objetos: Intimidad del espacio doméstico en tiempos de guardar distancia», in Titeteressante, abril de 2020, http://www.titeresante.es/2020/04/casa-y-teatro-de-objetos-intimidad-del-espacio-domestico-en-tiempos-de-guardar-distancia-por-shaday-larios/, consultado em 28 de setembro de 2020 .

PÁGINA da Companhia Oligor y Microscopia: https://oligorymicroscopia.org, consultada em 28 de setembro de 2020 . 